\title{
Estimating inelastic sediment deformation from local site response simulations
}

\author{
Ronaldo I. Borja $\cdot$ Wai Ching Sun
}

Received: 25 August 2007/Accepted: 21 September 2007/Published online: 6 October 2007

(c) Springer-Verlag 2007

\begin{abstract}
Significant insight into the dynamic local site response of a horizontally layered sediment deposit to seismic excitation can be gained from numerical simulations. In this paper we use a nonlinear local site response analysis code SPECTRA to estimate the coseismic sediment deformation at a seismically active site in Lotung, Taiwan. We address some basic issues relevant for interpreting the simulation results, including the impact of noise and baseline offsets present in the input ground motion. We also consider the sensitivity of the predicted deformation responses to statistical variations of sediment constitutive properties. Finally, we apply a suite of hypothetical strong ground motions to the base of the sediment deposit to better understand the pattern of inelastic deformation likely to result from strong seismic shaking.
\end{abstract}

Keywords Coseismic sediment deformation . Local site response - Plasticity - Seismicity ·

Strong ground motion

\section{Introduction}

Significant insight into the space-time coseismic deformation of a soil deposit can be gained from local site response simulations. By definition, coseismic sediment

R. I. Borja $(\bowtie) \cdot$ W. C. Sun

Department of Civil and Environmental Engineering,

Stanford University, Stanford, CA 94305, USA

e-mail: borja@stanford.edu

Present Address:

W. C. Sun

Department of Civil and Environmental Engineering,

Princeton University, Princeton, NJ 08541, USA

e-mail: wsun@princeton.edu deformation is the earthquake-induced residual displacement of the ground surface relative to the underlying bedrock. The free field ground motion, representing the dynamic response of a sediment deposit in the absence of a nearby superstructure, is now routinely quantified through local site response simulations. The predictive capability of a local site response model is measured by how closely it reproduces the measured acceleration-time history at the ground surface for a given bedrock excitation. Unfortunately, published works dealing with local site response of sediment deposits have not addressed the aspect of inelastic sediment deformation that is critical for assessing the performance of a soil-structure system. Part of the reason may be due to the fact that the most widely used nonlinear site response analysis code, SHAKE [17, 24], calculates the ground motion using an equivalent linear elastic procedure and hence does not predict any inelastic sediment deformation.

In principle, a fully nonlinear local site response analysis is necessary to quantify the inelastic deformation of a sediment deposit subjected to seismic excitation $[1,15,19$, 20, 22]. However, a majority of available nonlinear local site response analysis codes are difficult to use in practice because they require a considerable number of material parameters. Also, in general, the more complex the model the more difficult it is to calibrate. Of the fully nonlinear site response analysis codes available in the literature, SPECTRA $[5,7,8]$ is demonstrably as easy to use as SHAKE since the two codes require nearly the same material information to run. Furthermore, the sensitivity of SPECTRA to statistical variations in sediment constitutive properties has been shown to be comparable to that of SHAKE [3]. More recently, the algorithm used in SPECTRA has been implemented by some authors to analyze near-fault forward directivity ground motions [23]. In this 
paper we investigate the potential of SPECTRA for estimating the inelastic deformation of a sediment deposit resulting from seismic shaking. To make the study more specific we consider a sediment deposit at a well-studied large-scale seismic test (LSST) site in Lotung, Taiwan as a prototype case study.

Lotung is a seismically active region in northeastern Taiwan, and was the site of an extensive instrumentation array constructed by the Electric Power Research Institute and Taiwan Power Corporation for soil-structure interaction research $[12,13]$. The site contained a number of surface and downhole free-field instrumentation in a LSST array. Figure 1 shows the mechanical properties of the sediment at the LSST site. The local geological profile shows a layer of gray silty sand and sandy silt about $20 \mathrm{~m}$ thick, underlain by about $10 \mathrm{~m}$ of gravelly layer resting on a thick deposit of silty clay [26]. The water table is located approximately at a depth of $1.0 \mathrm{~m}$ [2]. Variation of the elastic shear modulus with depth was determined from seismic crosshole and uphole tests [2]. Shear modulus degradation and damping ratio curves were determined directly from the seismic response of the site from previous earthquakes [28]. Andrade and Borja [3] utilized the statistical variations of the constitutive properties of the sediment at the LSST site to construct a combined stochastic-deterministic model in an effort to quantify the model sensitivity to variations in soil properties.

In assessing the calculated displacement-time history, an important issue concerns the lack of purity of the recorded accelerograms since one must integrate the acceleration-time history twice to obtain the corresponding displacement-time history. Recorded accelerograms generally contain noise and/or baseline offsets of unknown origin that make an accurate numerical integration of the time-history response tricky. It must be noted that the difficulty arises only when calculating the displacementand velocity-time histories, since the impurities in the accelerogram prescribed at one point do not seem to significantly affect the resulting acceleration-time history calculated at another point.

There are several possible sources of noise and baseline offsets in the recorded accelerograms. They include mechanical [25] or electrical hysteresis in the sensor, problems with the analog-to-digital converter, and ground tilt and rotation [11, 27], due either to elastic deformation close to large ruptures or to inelastic deformation from slumping or cracking of the earth beneath the recording site [10]. In this paper, we show that the sediment deformation calculated by the code exhibits very little sensitivity to noise and baseline offsets contained in the input accelerograms. This is an important test of the robustness of a code since it provides for a meaningful local site response simulation independent of the biased processing of the recorded ground motions.

We also address the sensitivity of the predicted responses to statistical variations in sediment constitutive properties. Our rationale for this effort is that values of the sediment properties are known to have their own uncertainties, so a purely deterministic simulation is not meaningful. In order to address the statistical variations of sediment constitutive properties, we perform combined stochastic-deterministic simulations [3] and quantify the sensitivity of the predicted deformation responses to natural variations in the constitutive properties. Calculated deformations are expressed in terms of empirical cumulative distribution functions (ECDFs).

Finally, we attempt to establish patterns of inelastic deformation by applying a suite of hypothetical (for the site being considered) earthquakes to the sediment deposit and calculating the corresponding sediment deformations. Ground motions considered include those from moderately strong to very strong real earthquakes, with peak ground accelerations ranging from 0.10 to $1.75 \mathrm{~g}$. Our results indicate that there is no clear correlation between the inelastic residual deformation and peak ground acceleration - earthquakes with higher PGAs do not necessarily result in larger residual deformations. This result indicates that the PGA alone is not a sufficient predictor of coseismic deformation-one should consider the entire ground motion in the simulation to better estimate the inelastic coseismic sediment deformation. This observation could have important implications for how we utilize the Newmark sliding block method for calculating earthquake-induced sediment deformation.

\section{Time integration of accelerograms}

If the accelerograms were pure and a complete reproduction of the seismic event, they could be integrated twice to obtain the corresponding displacement-time histories. Shear deformation of a column of sediment could then be calculated simply by subtracting the horizontal displacement of one end point $A$ of the soil column from the horizontal displacement of another end point $B$ of the same soil column. However, accelerograms are never pure. The records produced by the sensors are combinations of signals representing the actual motion and the extraneous noise generated by insufficient decimal points in transcribing digitized data, tilting of the seismograph base, uncertainty in the initial conditions, and many other factors, see $[9-11,25,27]$. We illustrate this point with reference to the ground motions recorded at the LSST site in Lotung, Taiwan. 

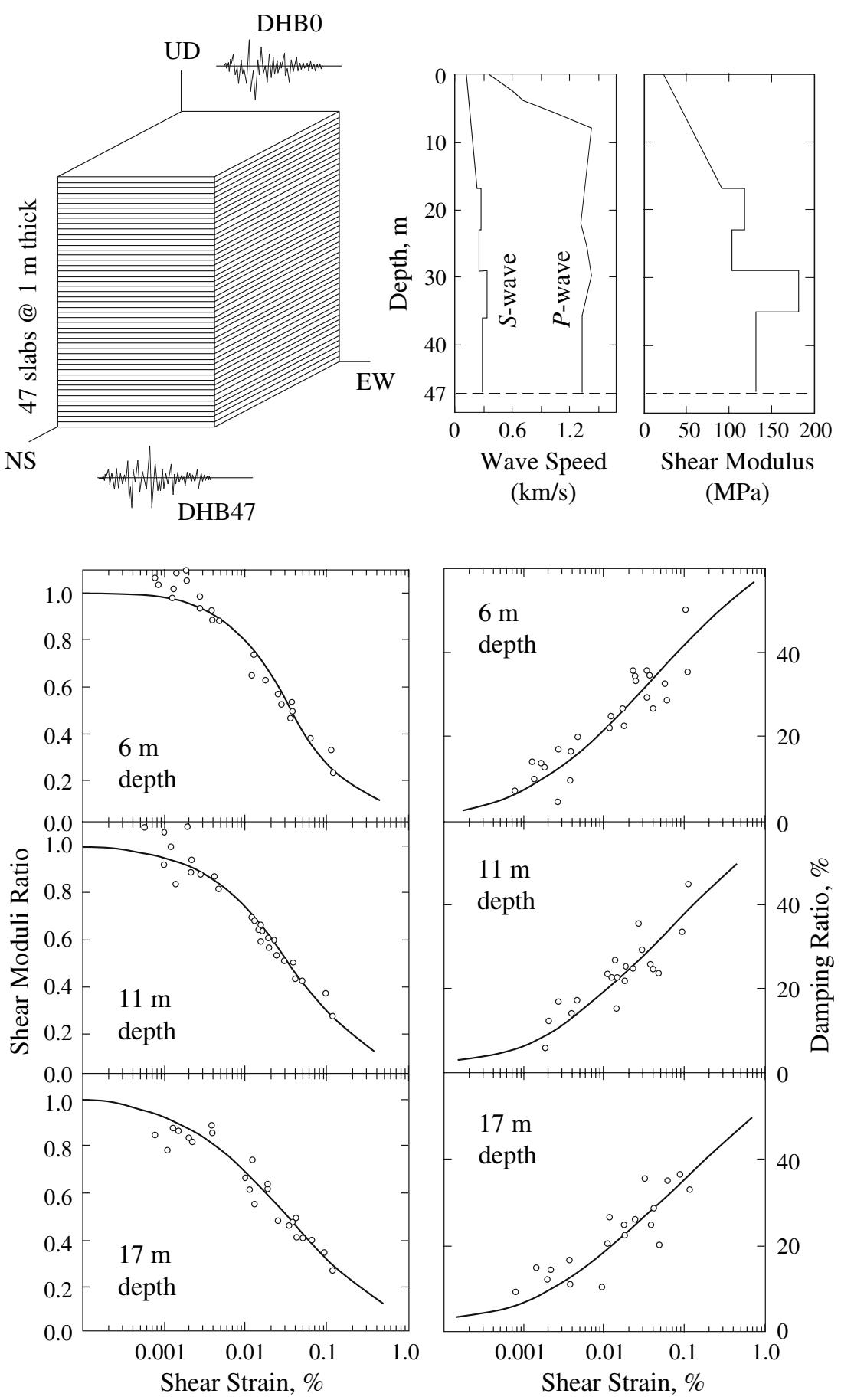

Fig. 1 Mechanical model for 47-m thick sediment deposit at LSST-downhole array DHB site in Lotung, Taiwan

At the LSST site in Lotung, Taiwan, a downhole array DHB recorded strong ground motion from a magnitude 6.5 earthquake of 20 May 1986, herein called the LSST7 event. Accelerograms were recorded at depths of $0,6,11,17$, and $47 \mathrm{~m}$. Figures 2 and 3 show unfiltered (raw) accelerograms for the east-west (EW) and north-south (NS) components of ground motion at depths 0 and $47 \mathrm{~m}$, respectively (denoted as DHB0 and DHB47 in Fig. 1). The accelerograms were integrated twice to yield the displacement-time histories also shown in the figures. As evident from the two figures, the displacement-time histories have not stabilized even as the ground accelerations have begun to die out. This suggests that the accelerograms contained noise and other impurities, and separating these extraneous elements from the actual motion poses a big challenge. The sensors at DHB0 and DHB47 were 

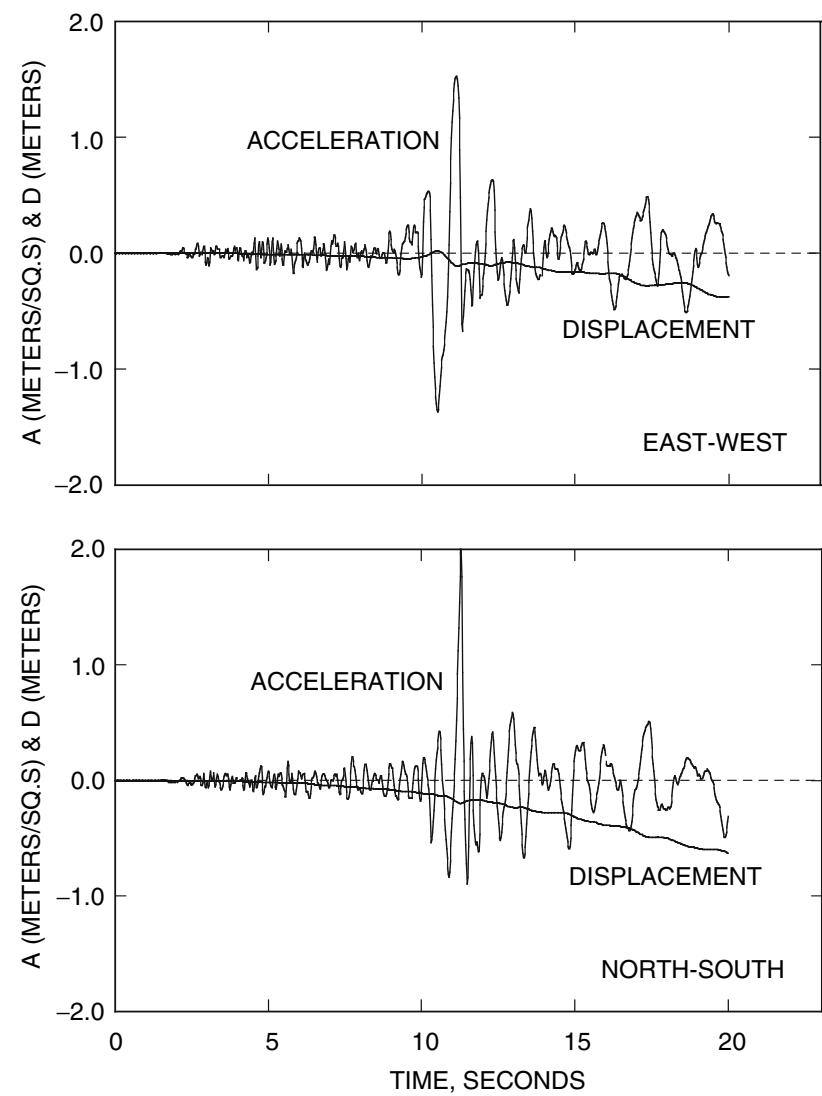

Fig. 2 Unfiltered (raw) acceleration and calculated displacementtime history plots at depth $0 \mathrm{~m}$ (ground surface) of downhole array DHB generated by the LSST7 earthquake of 20 May 1986

subjected to different environmental conditions, i.e., the extraneous components were not compensating, so subtracting the calculated displacements would not provide a meaningful estimate of the coseismic sediment deformation at the site.

Figures 4 and 5 show the same accelerograms for the EW and NS components of ground motion at depths 0 and $47 \mathrm{~m}$, respectively, after applying low pass filters to the original ground motion of $0.38 \mathrm{~Hz}$ for $\mathrm{EW}$ and $0.26 \mathrm{~Hz}$ for NS components. Our objective here is not to justify why we chose such filtering criteria nor to delve on the intent of the filters. Rather, we simply want to generate accelerograms that are quite similar to the unprocessed ones that contained impurities. We see that the filtered accelerograms shown in Figs. 4 and 5 look quite similar to those shown in Figs. 2 and 3. However, when numerically integrated the filtered accelerograms of Figs. 4 and 5 yielded very small residual displacements. In fact, the residual displacements depend on how the accelerograms have been filtered. Since filtering is a biased process, no objectively calculated displacements can be obtained from integrating the filtered accelerograms alone.
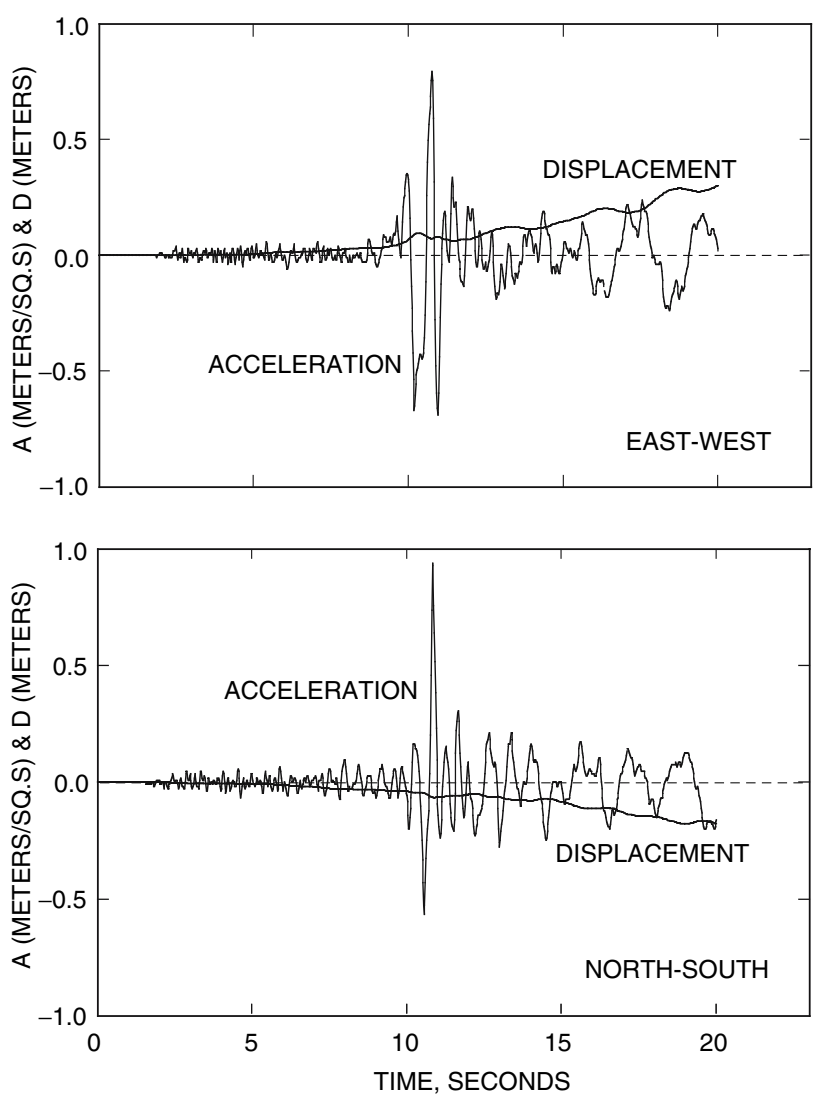

Fig. 3 Unfiltered (raw) acceleration and calculated displacementtime history plots at depth $47 \mathrm{~m}$ of downhole array DHB generated by the LSST7 earthquake of 20 May 1986

\section{Local site response simulations}

To estimate the inelastic sediment deformation objectively, the approach pursued in this paper consists of conducting nonlinear local site response simulations using the fully nonlinear site response analysis code SPECTRA. For this approach to be meaningful we need to demonstrate the following. First, the impurities in the input accelerograms should have little effect on the calculated inelastic deformation. Second, recognizing that the sediment constitutive properties follow some statistical distribution, we need to provide quantitative measures of the sensitivity of the deformation responses to statistical variations in the constitutive properties. Finally, since it would be very difficult to validate the predicted deformation response of a local site response code, we should at least demonstrate that the code is accurate enough to predict the recorded ground surface accelerograms.

For the LSST site the accuracy and predictive capability of SPECTRA have been documented in a number of previous publications, see Refs. [5, 7, 8]. In these papers, the calculated surface ground motions were shown to agree well enough with the recorded accelerograms at DHB0 for 

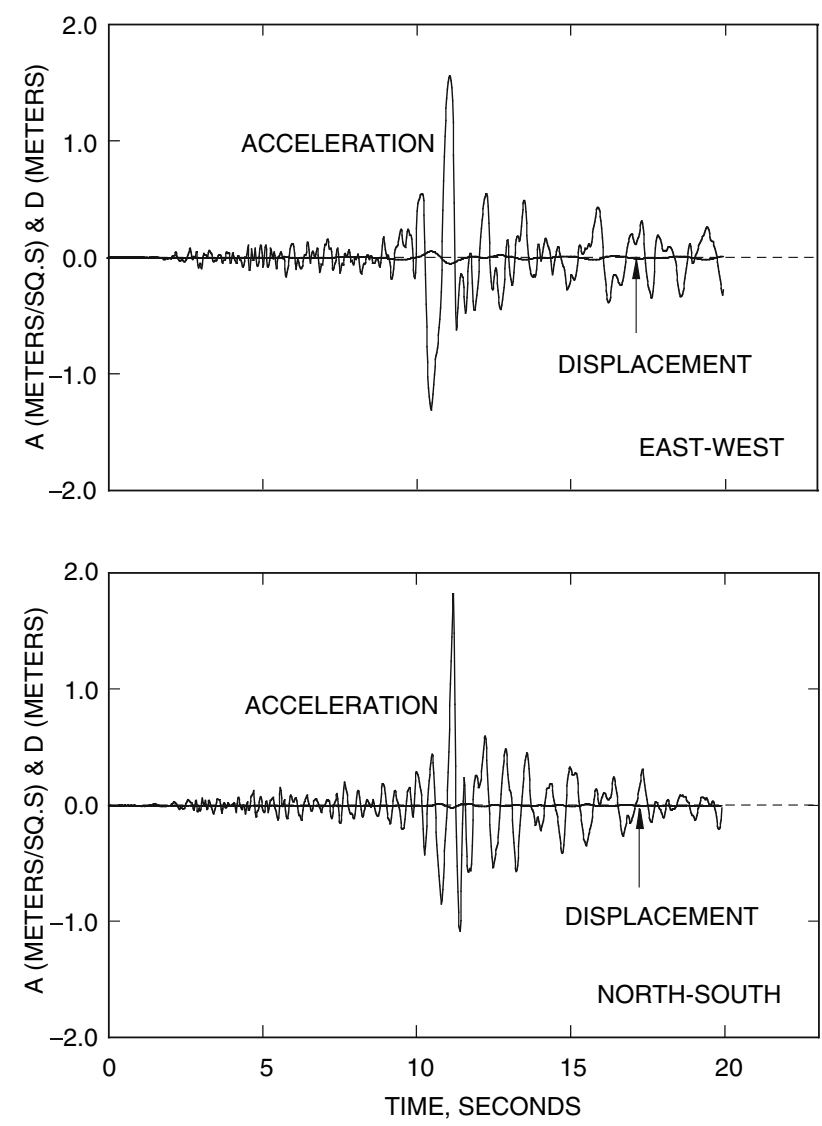

Fig. 4 Filtered acceleration and calculated displacement-time history plots at depth $0 \mathrm{~m}$ (ground surface) of downhole array DHB generated by the LSST7 earthquake of 20 May 1986. Residual displacements $=9.2 \mathrm{~mm}(\mathrm{EW})$ and $-0.1 \mathrm{~mm}(\mathrm{NS})$

a number of strong earthquakes, including the LSST7, LSSST12, and LSST16 earthquakes. Comparisons of the calculated and recorded surface ground motions were made in the form of acceleration-time histories, acceleration response spectra, Fourier acceleration amplitude spectra, and Arias intensity. Thus, the present section focuses only on the aspect of impurities in the accelerograms as well as on the quantification of model sensitivities.

\subsection{Effect of impurities in the input accelerogram}

With reference to Fig. 1, the local site response simulation consisted of applying an input excitation at DHB47 and calculating the acceleration-, velocity-, and displacementtime histories throughout the 47-m thick sediment deposit. Both the EW and NS horizontal components of ground motion from the LSST7 event were prescribed at the base of the sediment column. Each 1-m thick slab of the sediment column was represented by a constitutive model that utilizes a bounding surface plasticity theory with a vanishing elastic region [4], generalizing the one-dimensional kinematically hardening response presented in Ref. [14].
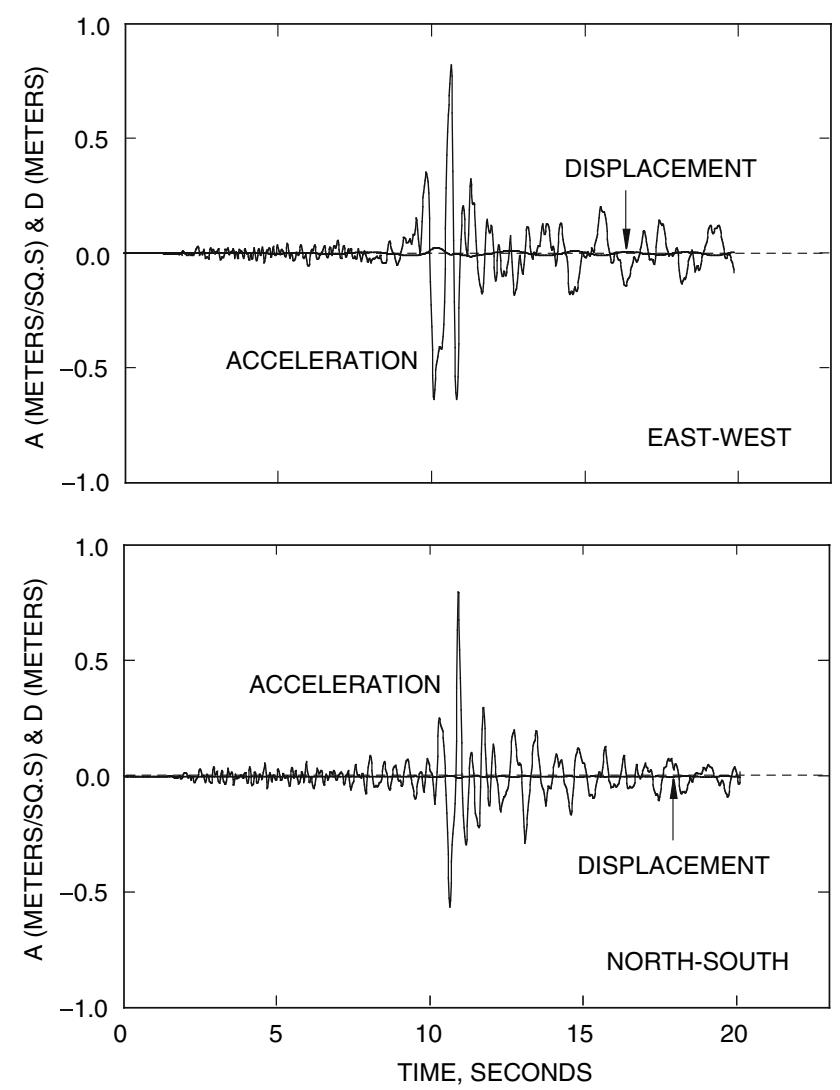

Fig. 5 Filtered acceleration and calculated displacement-time history plots at depth $47 \mathrm{~m}$ of downhole array DHB generated by the LSST7 earthquake of 20 May 1986. Residual displacements $=4.7 \mathrm{~mm}(\mathrm{EW})$ and $-1.7 \mathrm{~mm}(\mathrm{NS})$

Figure 1 summarizes the sediment constitutive properties used in the simulations. Time integration was carried out using the second-order accurate, unconditionally stable $\alpha$-method [16], with time integration parameters $\alpha=-0.10$, $\beta=0.3025$, and $\gamma=0.60$, and with a time step of $\Delta t=0.01 \mathrm{~s}$.

For purposes of estimating the coseismic deformation of the 47-m thick sediment column at the LSST site, the calculated horizontal displacement-time histories corresponding to raw and filtered accelerograms at DHB47 were subtracted from those calculated at DHB0, and the results are plotted in Figs. 6, 7 and 8. Figures 6 and 7 are nearly identical and simply demonstrate that two unconditionally stable second-order accurate time integration simulations utilizing different time integration parameters generated nearly the same responses. A number of observations can be made from Figs. 6 and 8. First, the maximum sediment deformation occurred during the period of intense ground shaking, and not at the conclusion of the earthquake. Second, the deformation "excursions" are quite similar for the two simulations. And, finally, the inelastic sediment deformations at the conclusion of the simulations are $2.18 \mathrm{~cm}$ for raw and 


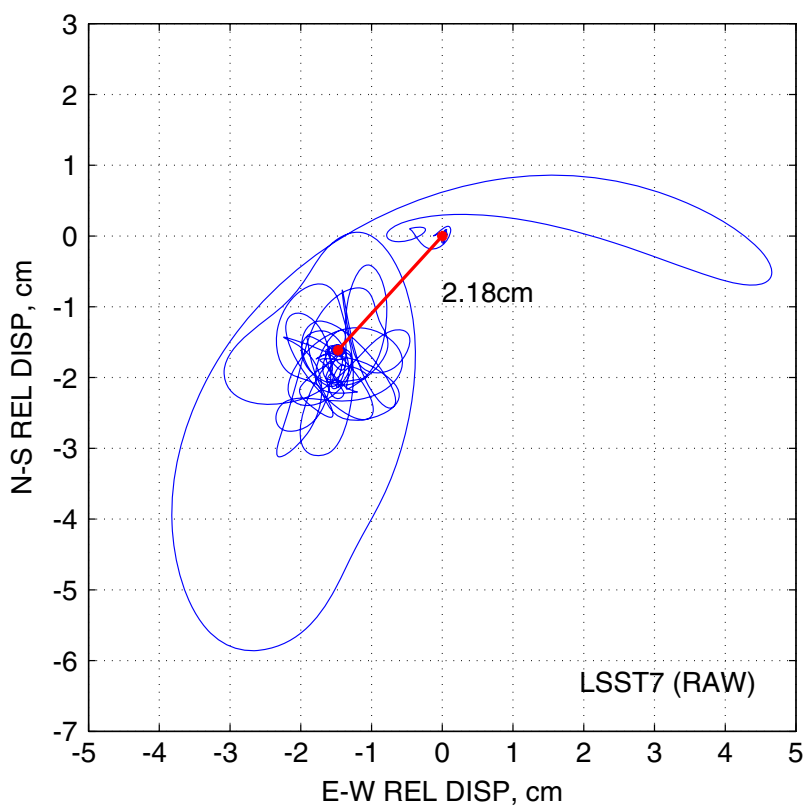

Fig. 6 Coseismic deformation of a 47-m thick sediment deposit at Lotung downhole array DHB generated by the LSST7 earthquake of 20 May 1986. Simulation was conducted using raw acceleration-time forcing function at depth $47 \mathrm{~m}$ along with the $\alpha$-time integration method $(\Delta t=0.01 \mathrm{~s}, \alpha=-0.10, \beta=0.3025$, and $\gamma=0.60)$

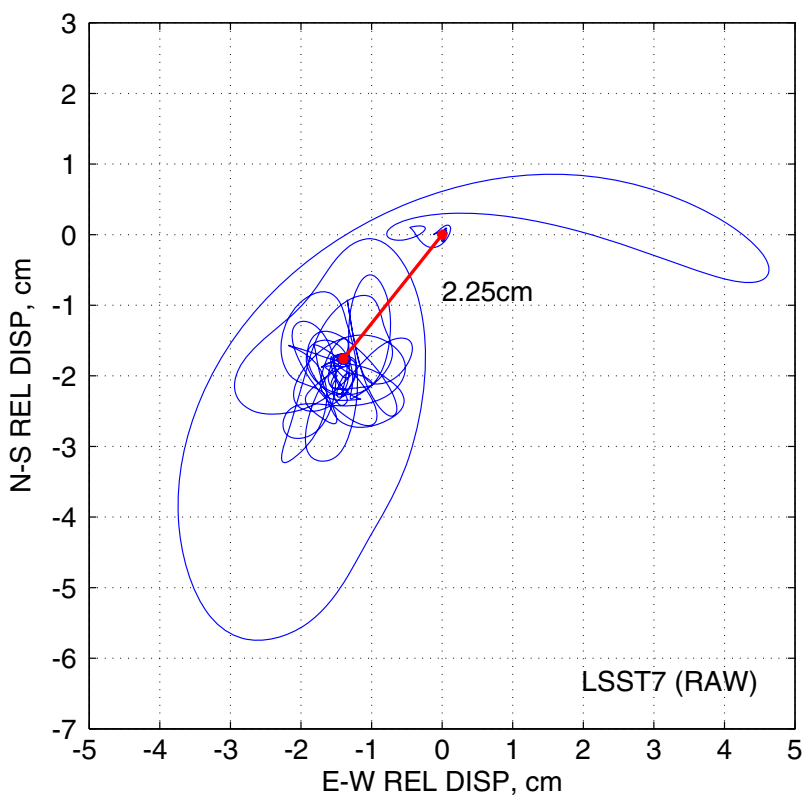

Fig. 7 Coseismic deformation of a 47-m thick sediment deposit at Lotung downhole array DHB generated by the LSST7 earthquake of 20 May 1986. Simulation was conducted using raw acceleration-time forcing function at depth $47 \mathrm{~m}$ along with the average acceleration method $(\Delta t=0.01 \mathrm{~s}, \beta=0.25, \gamma=0.50)$

$2.26 \mathrm{~cm}$ for filtered accelerograms, for a difference of only $4 \%$. Considering the complexity of the ground motions, this difference is negligible and suggests that

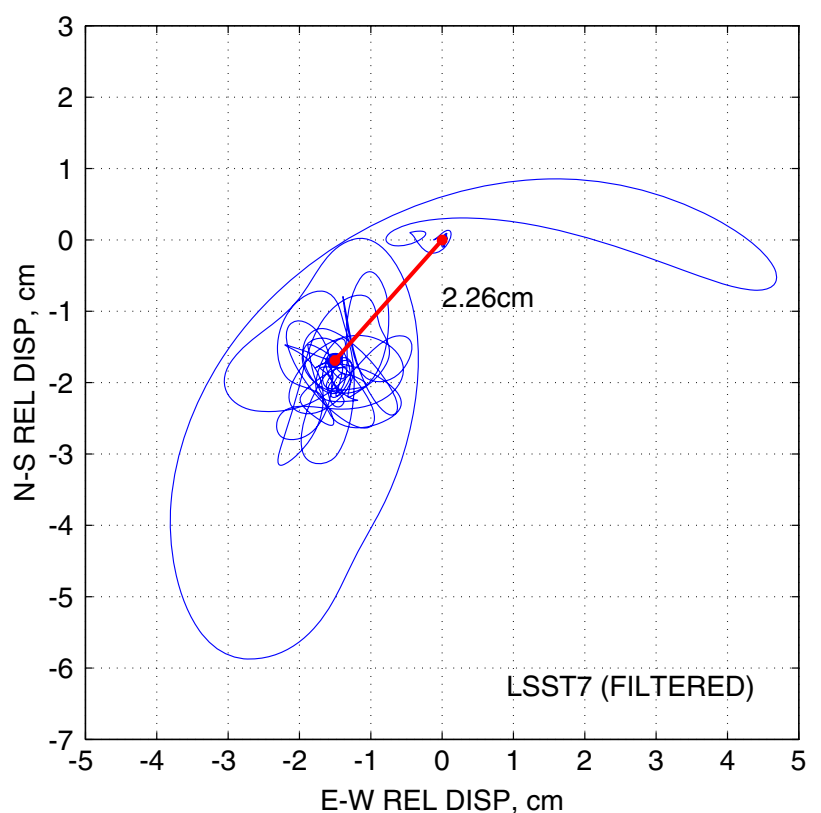

Fig. 8 Coseismic deformation of a 47-m thick sediment deposit at Lotung downhole array DHB generated by the LSST7 earthquake of 20 May 1986. Simulation was conducted using filtered accelerationtime forcing function at depth $47 \mathrm{~m}$ along with the $\alpha$-time integration method $(\Delta t=0.01 \mathrm{~s}, \alpha=-0.10, \beta=0.3025$, and $\gamma=0.60)$

impurities in the accelerograms have very little effect on the calculated local site responses.

That the impurities in the accelerograms have very little effect on the calculated inelastic sediment deformation may be explained from the following: Baseline offsets in the accelerogram produce nearly constant residual velocities as can be seen from the nearly linear increase of residual displacements in Figs. 2 and 3. This implies that the entire sediment column simply translates as a rigid body at the conclusion of the simulation. Where the residual velocity is not constant, the rate of change is too small to produce significant inelastic deformation. Thus, whereas noise and baseline offsets make it difficult to calculate the absolute residual displacement of a point in a soil column, they have very little effect on the relative residual displacements of two points in the same soil column.

\subsection{Combined stochastic-deterministic simulations}

The combined stochastic-deterministic simulations were carried out following the procedure proposed in Ref. [3]. The input excitation was treated as a deterministic forcing function $U$, while the parameter set $V$ of the constitutive model was treated as a set of random variables with given probability distributions (see Ref. [4] for the specific material parameters treated as random variables). The response function $f_{i}$ is the residual coseismic deformation itself, i.e., 


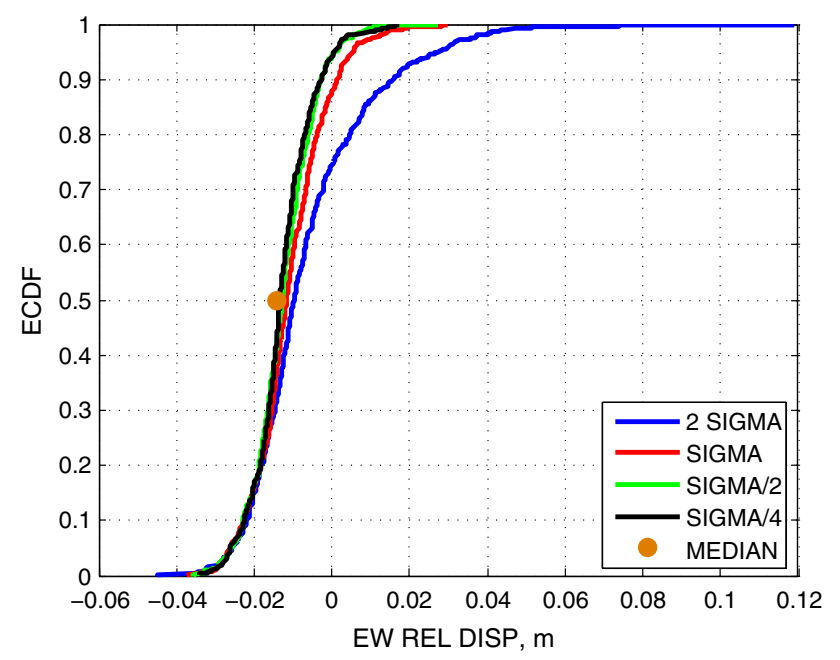

Fig. 9 Empirical cumulative distribution function for EW component of coseismic relative displacement

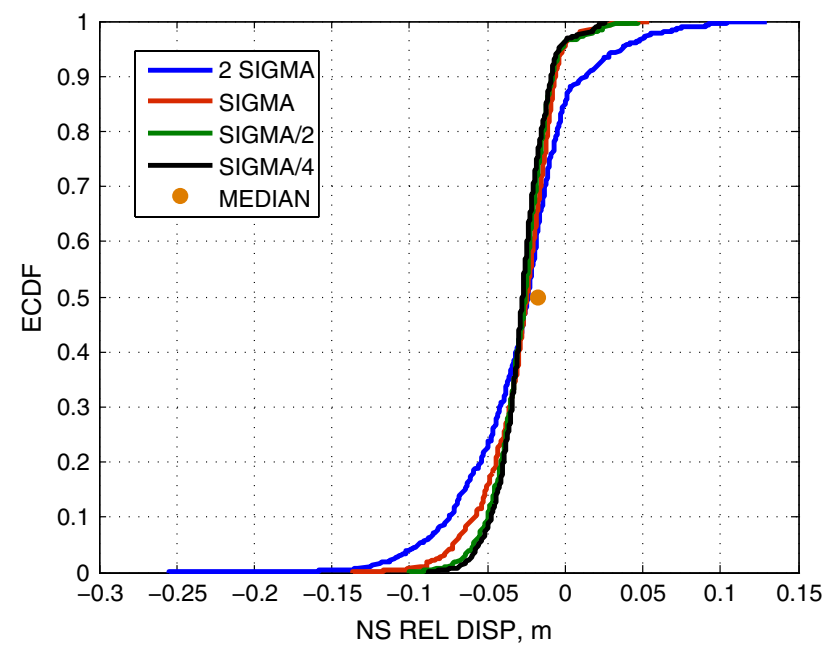

Fig. 10 Empirical cumulative distribution function for NS component of coseismic relative displacement

$f_{i}=f_{i}(U, V), \quad i=\mathrm{EW}, \mathrm{NS}$.

Seven hundred realizations were generated for each direction by the structural reliability computer program CARDINAL [3], which were then input into SPECTRA to calculate the associated residual and maximum deformations. For the record, the residual deformation was calculated at the end of the time history or after a certain time duration when the residual deformation has converged to a sufficiently stable value.

Empirical cumulative distribution functions in the EW and NS directions were obtained from Monte Carlo simulations with the LSST7 event as the deterministic forcing function. They are shown in Figs. 9 and 10, respectively. Four ECDFs were generated for each direction. The ECDF curves represent the distributions of the magnitude of coseismic deformation (a scalar function) corresponding to the mean values of soil parameters and four sets of standard deviations that are scaled by factors of 1/4, 1/2, 1 and 2 . The computed coseismic deformation obtained by using the median soil property parameters is labeled as MEDIAN in Figs. 9 and 10.

The sensitivity of the coseismic deformation can be quantified by two measures: the coefficient of variation $(\mathrm{COV})$, defined as the ratio between the standard deviation and the mean of the random variable, and the probability of the coseismic deformation falling into an acceptable range. Random variables with COV larger than 1 are considered high-variance, while random variables with COV smaller than 1 are considered low-variance. As for the second measure of sensitivity, we compared the "relative distance" from the deterministic response at the median parameters and calculated the probability that the response function falls into an acceptable range. More specifically, we defined the "relative distance" as

$d=\frac{f(U, V)-f\left(U, V_{0.5}\right)}{f\left(U, V_{0.5}\right)}$,

and calculated the probability that $|d|<0.20$. To make the sensitivity analysis meaningful, we compared the sensitivity of the coseismic deformation to that of Arias intensity, the response function studied in Ref. [3], for the same ground motion.

The COV of the coseismic deformation for $1 / 4,1 / 2,1$, and 2 SIGMA models are found to be $0.61,0.65,0.89$ and 2.80 in the EW direction; and $0.60,0.68,0.80$, and 1.40 in NS direction, respectively. From Ref. [3], the COV for Arias intensity at $1 / 2$ and 1 SIGMA models are 0.24 and 0.42 , respectively. On the other hand, the probability of the computed coseismic deformation falling into the acceptable range $|d|<0.2$ are $0.27,0.28,0.24$ and 0.25 in the EW direction, and $0.69,0.65,0.58$ and 0.55 for the NS directions, corresponding to $1 / 4,1 / 2,1$, and 2 SIGMA models. These results suggest that the coseismic deformation response function exhibits slightly higher COV compared to the Arias intensity response function. As noted earlier, inelastic deformation is a more difficult response function to predict with a greater certainty than the acceleration, so there is a correspondingly higher sensitivity to parameter variation of this response function as compared to Arias intensity.

\section{Patterns of inelastic deformation}

For monotonic loading inelastic deformation is expected to increase monotonically. However, for earthquake loading a material point can return to its original position even after experiencing considerable inelastic deformation if the ground motion is "self-restoring." We thus expect that the 
Table 1 Strong ground motions applied at the base of the LSST sediment model to study patterns of inelastic deformation

\begin{tabular}{|c|c|c|c|c|}
\hline Number & Event (magnitude ${ }^{\mathrm{a}}$ ) & Date & Station & $\operatorname{PGA}(g)^{\mathrm{b}}$ \\
\hline 1 & $\operatorname{LSST7}\left(M_{\mathrm{W}} 6.5\right)$ & 20 May 1986 & DHB47 & 0.10 \\
\hline 2 & $\operatorname{LSST7}(2 \times)$ & 20 May 1986 & DHB47 & 0.20 \\
\hline 3 & LSST7 (4×) & 20 May 1986 & DHB47 & 0.40 \\
\hline 4 & Chi-Chi1 $\left(M_{\mathrm{S}} 7.6\right)$ & 20 September 1999 & CHY028 & 0.89 \\
\hline 5 & Chi-Chi2 $\left(M_{\mathrm{S}} 7.6\right)$ & 20 September 1999 & CHY006 & 0.39 \\
\hline 6 & Big Bear $\left(M_{\mathrm{S}} 6.6\right)$ & 28 June 1992 & Civic Center Ground & 0.65 \\
\hline 7 & El Centro $\left(M_{\mathrm{S}} 7.2\right)$ & 18 May 1940 & EC Terminal Station & 0.35 \\
\hline 8 & Hawaii $\left(M_{\mathrm{L}} 6.7\right)$ & 15 October 2006 & Waima Fire Station & 1.12 \\
\hline 9 & Loma Prieta $\left(M_{\mathrm{S}} 7.1\right)$ & 17 October 1989 & Gilroy 1 & 0.50 \\
\hline 10 & Morgan Hill $\left(M_{\mathrm{S}} 6.1\right)$ & 24 April 1984 & Coyote Lake Dam & 1.18 \\
\hline 11 & Northridge $\left(M_{\mathrm{S}} 6.7\right)$ & 17 January 1994 & UCLA Ground & 0.52 \\
\hline 12 & Petrolia $\left(M_{\mathrm{L}} 7.1\right)$ & 25 April 1992 & Cape Mendocino & 1.75 \\
\hline
\end{tabular}

${ }^{\text {a }} M_{\mathrm{L}}=$ Richter, $M_{\mathrm{S}}=$ surface wave, $M_{\mathrm{W}}=$ moment

b Resolved horizontal PGA, equal to $\sqrt{a_{\mathrm{NS}}^{2}+a_{\mathrm{EW}}^{2}}$

Table 2 Dominant frequency $f_{\text {dom }}$, angular frequency $\omega_{\text {dom }}=2 \pi f_{\text {dom }}$, and estimated viscous damping coefficent $\chi=2 \xi_{0} / \omega_{\text {dom }}$, where $\xi_{0}$ is asymptotic damping ratio at zero shear strain, for strong ground motions applied at the base of the LSST sediment model

\begin{tabular}{lllcl}
\hline Number & Event $($ magnitude $)$ & $f_{\text {dom }}(\mathrm{Hz})$ & $\omega_{\text {dom }}(\mathrm{rad} / \mathrm{s})$ & $\chi$ \\
\hline 1 & LSST7 $\left(M_{\mathrm{W}} 6.5\right)$ & 0.65 & 4.1 & 0.10 \\
2 & LSST7 $(2 \times)$ & 0.65 & 4.1 & 0.20 \\
3 & LSST7 $(4 \times)$ & 0.65 & 4.1 & 0.40 \\
4 & Chi-Chi1 $\left(M_{\mathrm{S}} 7.6\right)$ & 1.19 & 7.5 & 0.89 \\
5 & Chi-Chi2 $\left(M_{\mathrm{S}} 7.6\right)$ & 1.60 & 10.1 & 0.39 \\
6 & Big Bear $\left(M_{\mathrm{S}} 6.6\right)$ & 2.98 & 18.7 & 0.65 \\
7 & El Centro $\left(M_{\mathrm{S}} 7.2\right)$ & 1.47 & 9.2 & 0.35 \\
8 & Hawaii $\left(M_{\mathrm{L}} 6.7\right)$ & 6.00 & 37.7 & 1.12 \\
9 & Loma Prieta $\left(M_{\mathrm{S}} 7.1\right)$ & 2.67 & 16.8 & 0.50 \\
10 & Morgan Hill $\left(M_{\mathrm{S}} 6.1\right)$ & 1.29 & 8.1 & 1.18 \\
11 & Northridge $\left(M_{\mathrm{S}} 6.7\right)$ & 4.11 & 25.8 & 0.52 \\
12 & Petrolia $\left(M_{\mathrm{L}} 7.1\right)$ & 3.55 & 22.3 & 1.75 \\
\hline
\end{tabular}

The elastoplastic constitutive model automatically generates hysteretic damping

${ }^{a} M_{\mathrm{L}}=$ Richter, $M_{\mathrm{S}}=$ surface wave, $M_{\mathrm{W}}=$ moment

peak ground acceleration alone, or even the more commonly used measure of "yield acceleration," would not be a sufficient predictor of coseismic inelastic deformation. To demonstrate this point, we applied a suite of strong ground motions at the base of the 40-m thick LSST sediment model and deterministically calculated the resulting maximum and residual inelastic deformations. We had a choice of generating synthetic ground motions with different amplitudes, duration, frequency contents, etc. Alternatively, we deemed it more insightful to select a suite of ground motions with different signatures from previous earthquakes and applied them to the soil column model.
Most of the ground motions considered were collected from the websites of the US National Center for Engineering Strong Motion Data ${ }^{1}$ and Pacific Earthquake Engineering Research Center. ${ }^{2}$ Raw data from the LSST site were provided by the Electric Power Research Institute, while raw data from the Loma Prieta earthquake were provided by California Geological Survey. Tables 1 and 2 summarize the 12 ground motions considered in this study, including those recorded from the Big Bear, El Centro, Hawaii, Loma Prieta, Morgan Hill, Northridge, and Petrolia earthquakes. In addition, we selected two ground motions (strong and moderately strong) from Chi-Chi earthquake, along with the LSST7 ground motions magnified two and four times. Resolved horizontal PGAs ranged from 0.10 to $1.75 \mathrm{~g}$. These ground motions have different signatures that could help shed light onto the pattern of inelastic deformation.

Times histories of calculated relative displacements are shown in Figs. 11, 12, 13, 14, 15, 16, 17, 18, 19, 20 and 21. Some notable observations are as follows. Figures 11 and 12 suggest that simply scaling the input accelerograms (LSST7 magnified $2 \times$ and $4 \times$, respectively) could drastically change the relative displacement time histories. In the case of Petrolia earthquake (Fig. 21) the ground motions were nearly self-restoring in the sense that the calculated residual relative displacements were much smaller than the maximum relative displacements, making the response appear "elastic." In all cases, the solutions were convergent in the sense that there was a fixed point in the relative displacement space at which the "excursions" appeared to have stabilized. The distance between this

\footnotetext{
1 http://www.strongmotioncenter.org.

2 http://peer.berkeley.edu/smcat/search.html.
} 


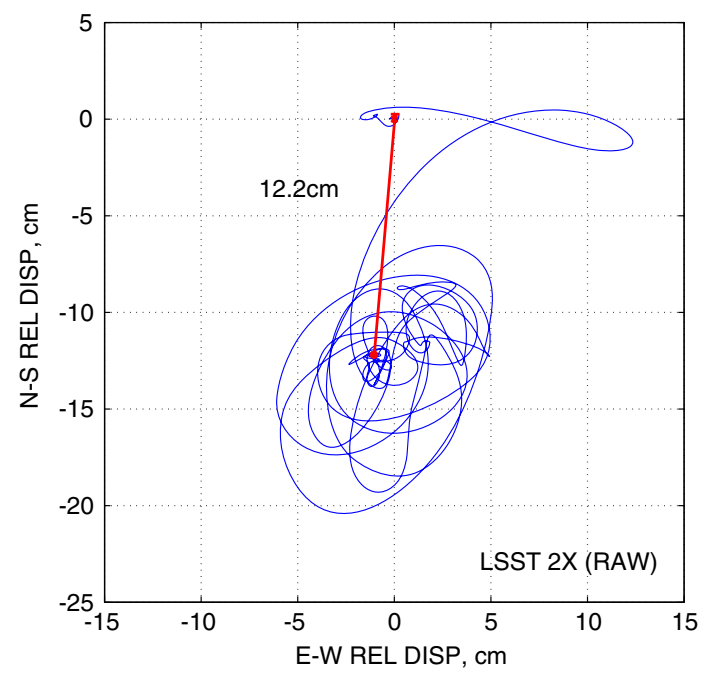

Fig. 11 Coseismic relative displacement resulting from LSST7 ground motion magnified two times

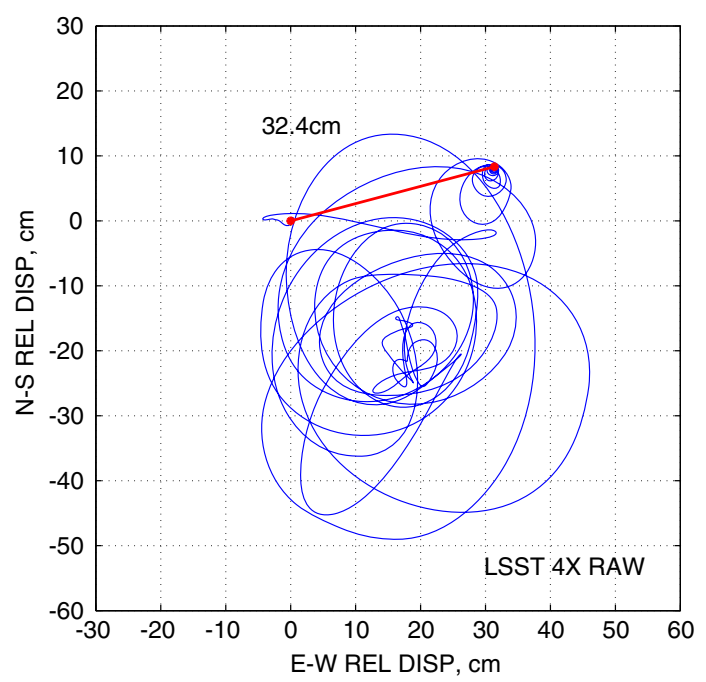

Fig. 12 Coseismic relative displacement resulting from LSST7 ground motion magnified four times

point and the origin of the relative displacement space measures the residual coseismic deformation, whereas the maximum distance from the origin at any given time is the maximum coseismic deformation.

Data from Figs. 11, 12, 13, 14, 15, 16, 17, 18, 19, 20 and 21 are summarized in Figs. 22 and 23, where the residual and maximum relative displacements are plotted versus the resolved horizontal PGA. Note that data points are all scattered, i.e., there is no clear correlation between relative displacements and PGAs. Specifically, the strongest ground motion considered from the Petrolia earthquake (data point \#12) generated relatively small residual deformation, even if the maximum deformation was quite significant. By comparison, the ground motion from Hawaii earthquake

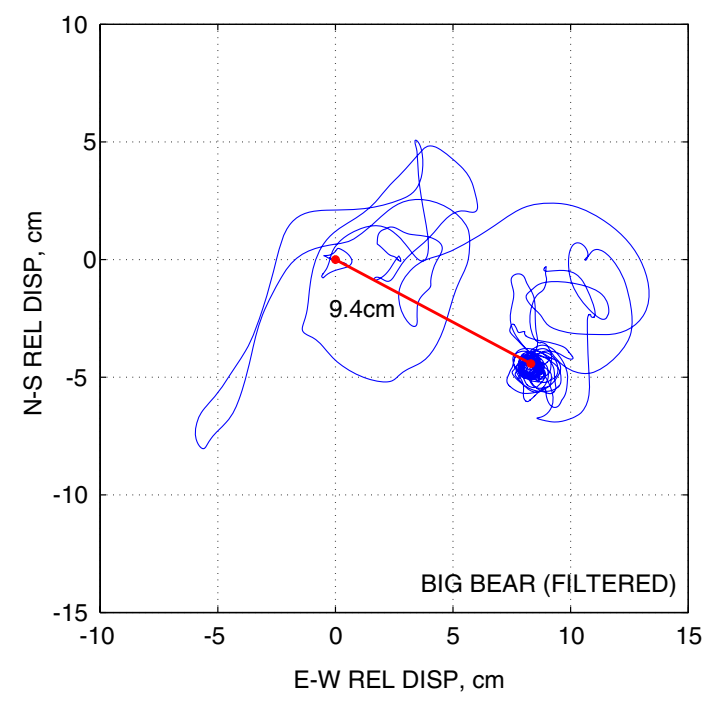

Fig. 13 Coseismic relative displacement resulting from Big Bear ground motion

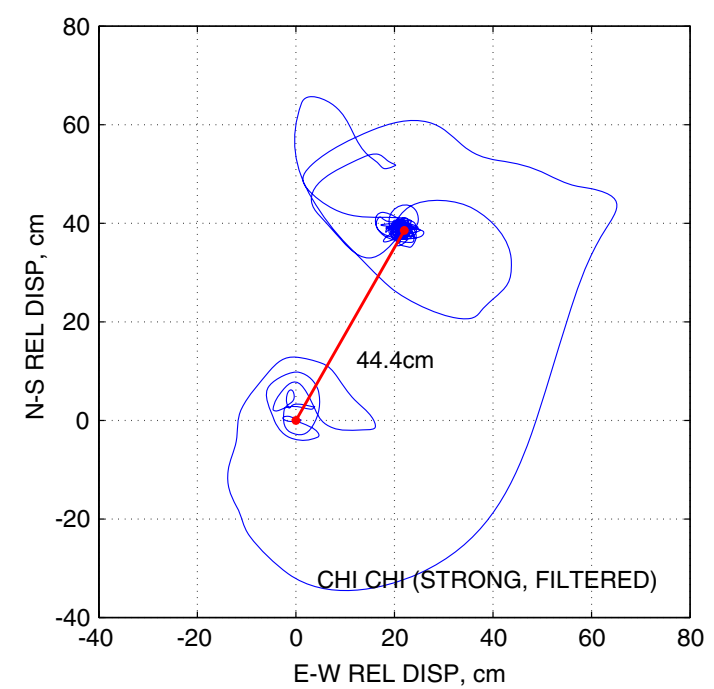

Fig. 14 Coseismic relative displacement resulting from Chi-Chi ground motion with peak ground acceleration of $0.89 \mathrm{~g}$

had the second highest PGA but produced relatively small maximum relative displacement. The Hawaii ground motion had uniform, nearly sinusoidal strong pulses that were out of resonance with the sediment deposit, thus generating deformations that were much smaller than those produced by some of the weaker ground motions.

To investigate the effect of resonance and frequency mismatch on the residual and maximum relative displacements, we performed an eigenvalue analysis on the mechanical model shown in Fig. 1 utilizing the depthvarying elastic properties of the sediments at the LSST site. In general, the eigenvalue analysis should incorporate the degradation of shear moduli with deformation. However, we only used the elastic properties to determine the 


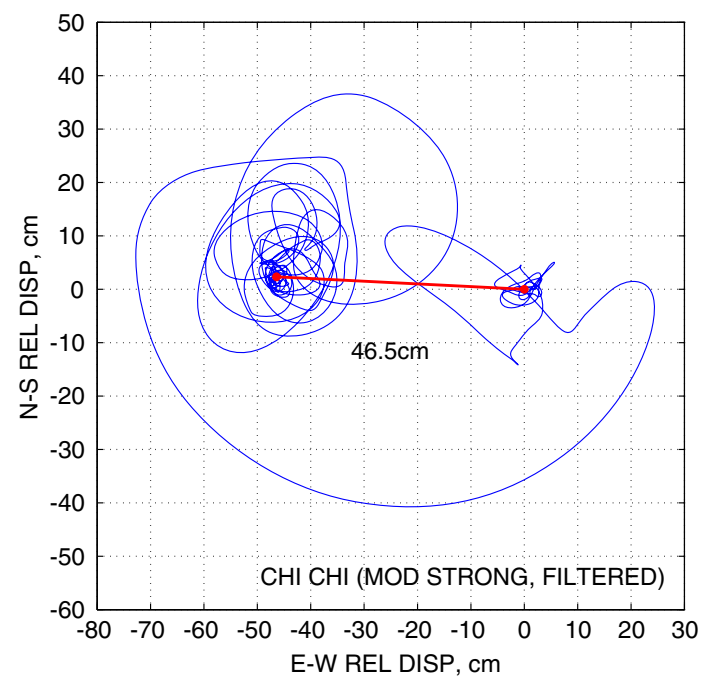

Fig. 15 Coseismic relative displacement resulting from Chi-Chi ground motion with peak ground acceleration of $0.39 \mathrm{~g}$

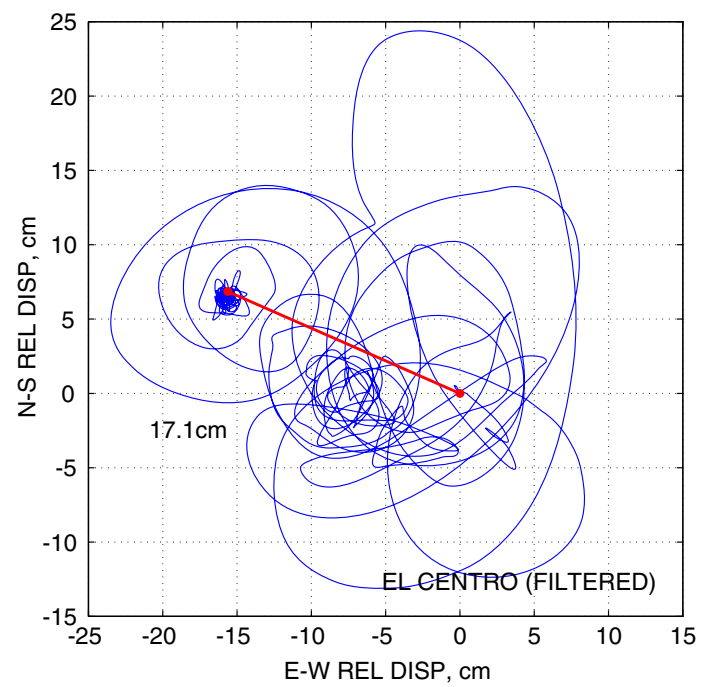

Fig. 16 Coseismic relative displacement resulting from El Centro ground motion

fundamental frequencies of vibration and the associated eigenmodes of the sediment column. Figure 24 shows the first six modes of vibration reported in Ref. [6] for the sediment column model. Repeated modes were detected for the EW and NS components, so the figure effectively shows only the first three distinct modes of vibration. Comparing with the dominant frequencies of the ground motions summarized in Table 2, we see that the ground motion from the Hawaii earthquake $\left(f_{\text {dom }}=6 \mathrm{~Hz}\right)$ triggered only the fifth and sixth modes $(f=5.9 \mathrm{~Hz})$, and hence produced small relative deformations even if the input PGA was very high. Comparing the ground motions from Chi-Chil and ChiChi2, the former had a PGA more than twice that of the latter ground motion, yet both ground motions produced

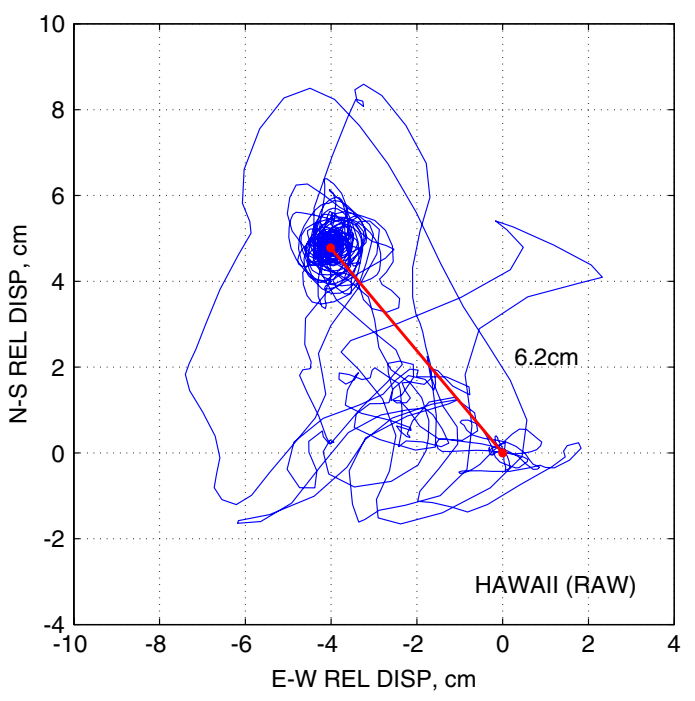

Fig. 17 Coseismic relative displacement resulting from Hawaii ground motion

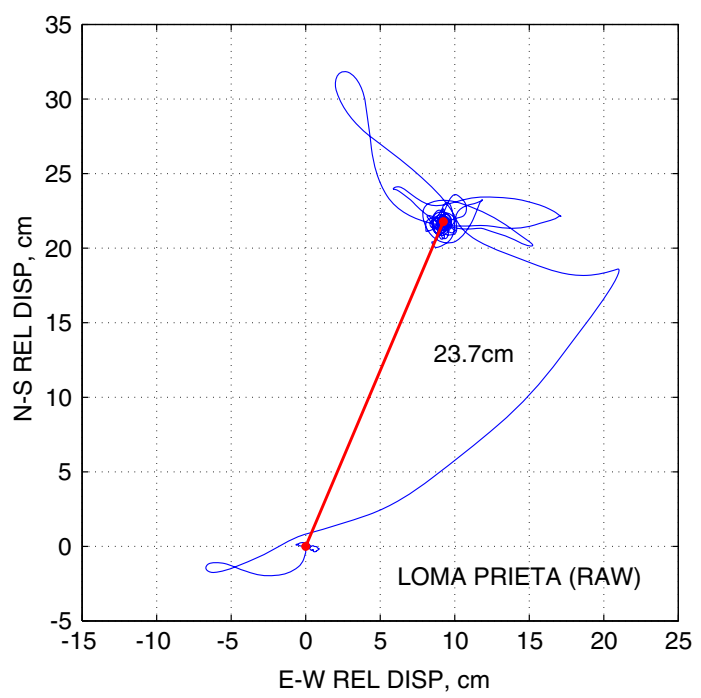

Fig. 18 Coseismic relative displacement resulting from Loma Prieta ground motion

nearly the same residual and maximum relative displacements (data points 4 and 5 in Figs. 22, 23). This is because Chi-Chi2 $\left(f_{\text {dom }}=1.60 \mathrm{~Hz}\right)$ triggered the first mode $(f=1.4 \mathrm{~Hz})$, and thus amplified the ground motion.

The results of the above simulations lead to the conclusion that inelastic deformations cannot be predicted from the PGA alone. Other factors such as the duration, frequency content, and other important aspects of the ground motion should be considered in the simulation. A truly nonlinear model such as the one used in this work can capture these effects, provided that the analyst considers the entire history of ground motion and the simulationn is terminated at a point where the deformation excursions appear 


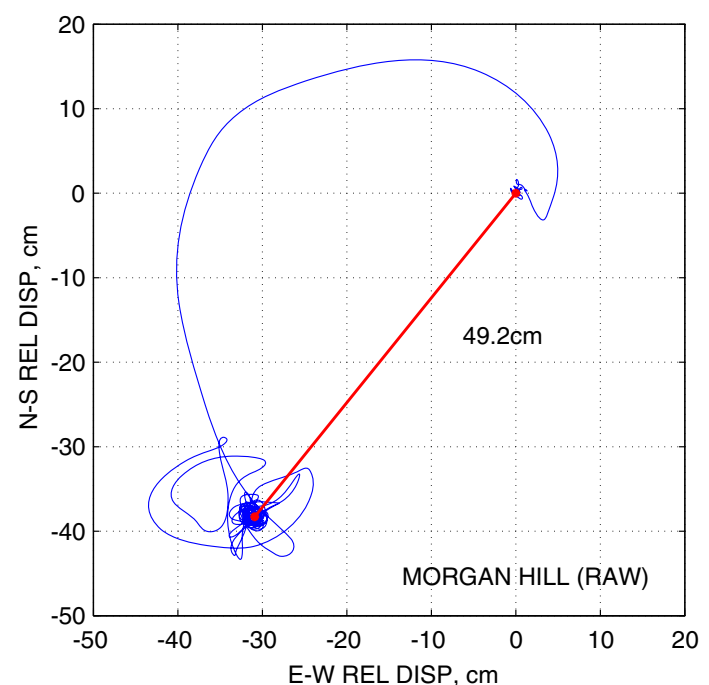

Fig. 19 Coseismic relative displacement resulting from Morgan Hill ground motion

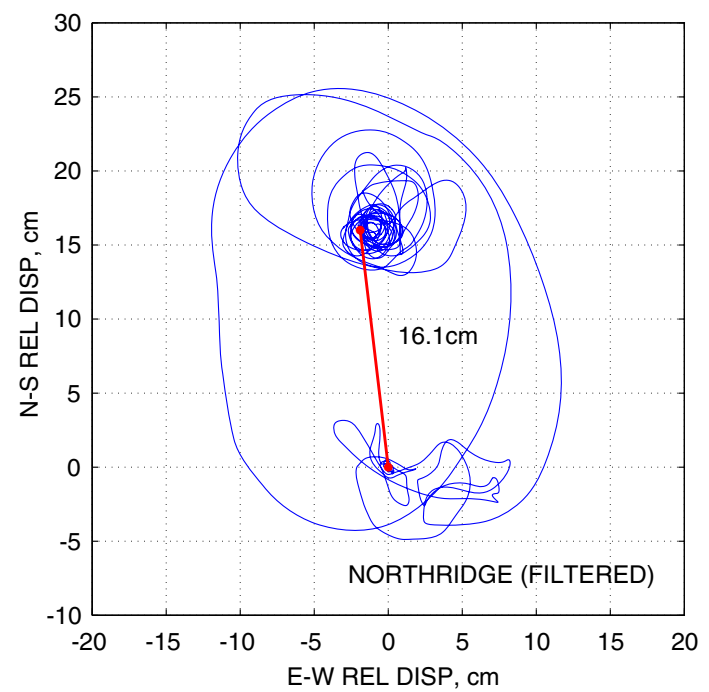

Fig. 20 Coseismic relative displacement resulting from Northridge ground motion

to have stabilized. Currently, coseismic permanent ground deformations are estimated using a procedure based on the notion of yield acceleration [18]. This procedure treats the two horizontal components of ground motion separately, and only calculates the permanent ground motion, using the Newmark sliding block procedure [21], once a certain threshold of acceleration is reached. In contrast, the nonlinear simulation approach used in this work uses the entire history of ground motion and the coupled the EW-NS mechanical responses to calculate the inelastic deformation. Modeling the coupled EW-NS mechanical response and accounting for the entire history of ground motion could significantly improve the accuracy of the simulations.

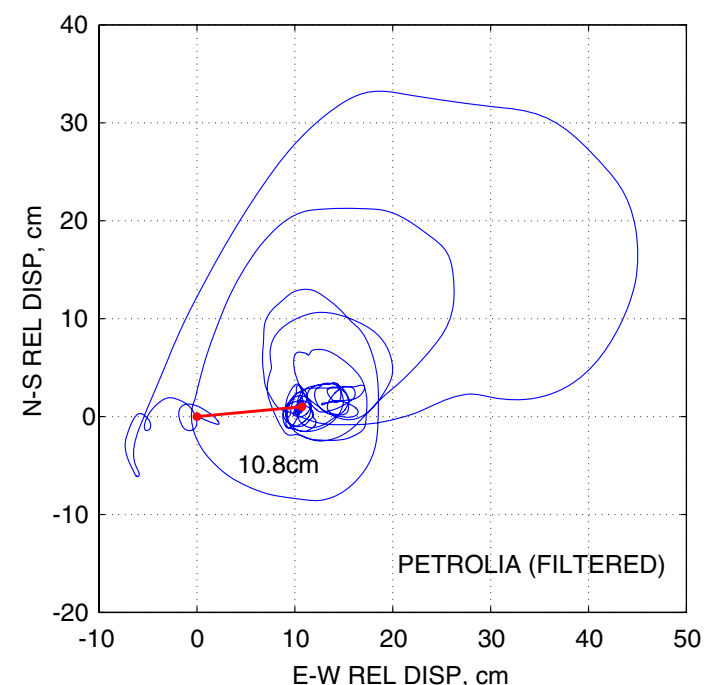

Fig. 21 Coseismic relative displacement resulting from Petrolia ground motion

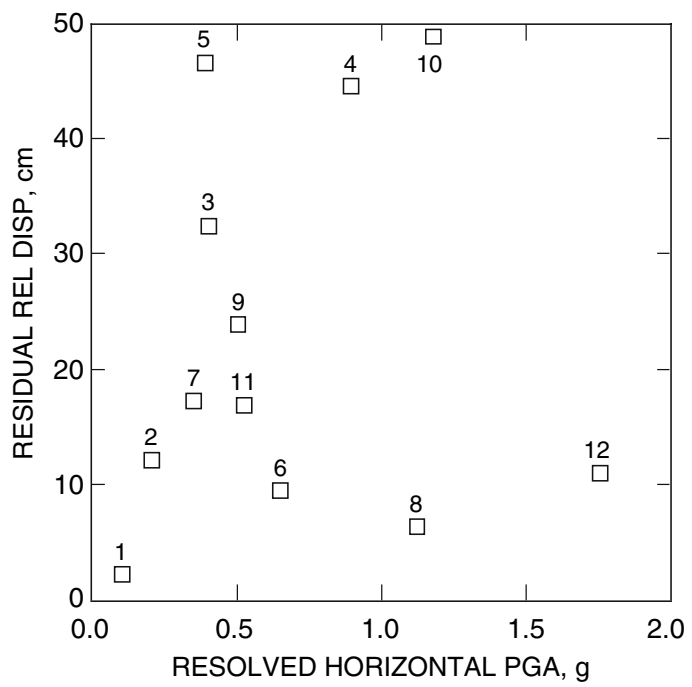

Fig. 22 Coseismic residual sediment deformation at LSST site versus resolved horizontal PGA. Numbers next to data points pertain to ground motions described in Table 1

\section{Summary and conclusions}

We have used nonlinear local site response simulation to estimate the inelastic deformation of a horizontally layered deposit of soft soil under an imposed bedrock excitation. The impact of noise and baseline offset on the calculated deformation has been quantified and was shown to be insignificant, supporting the use of the nonlinear simulation approach for estimating the inelastic coseismic deformation. We have also quantified the sensitivity of the nonlinear model to statistical variation in sediment constitutive properties. To this end, ECDFs have been 


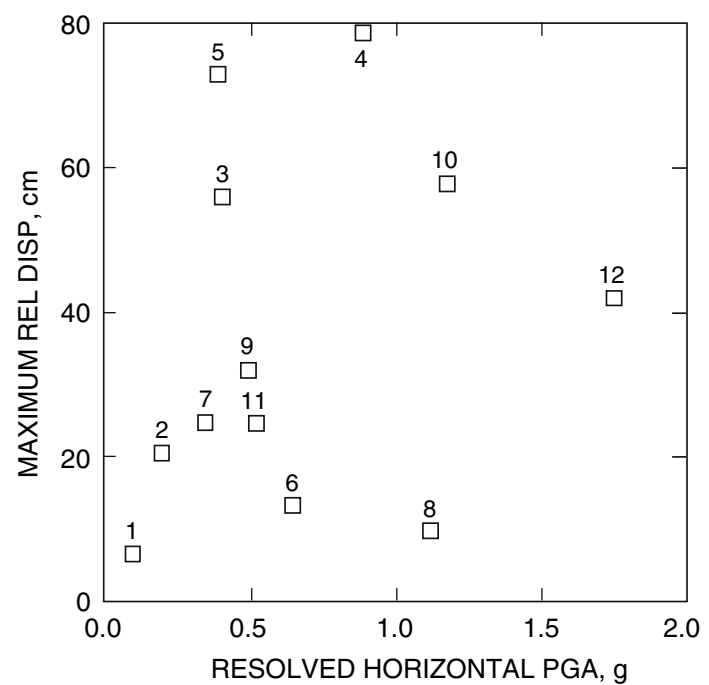

Fig. 23 Coseismic maximum sediment deformation at LSST site versus resolved horizontal PGA. Numbers next to data points pertain to ground motions described in Table 1
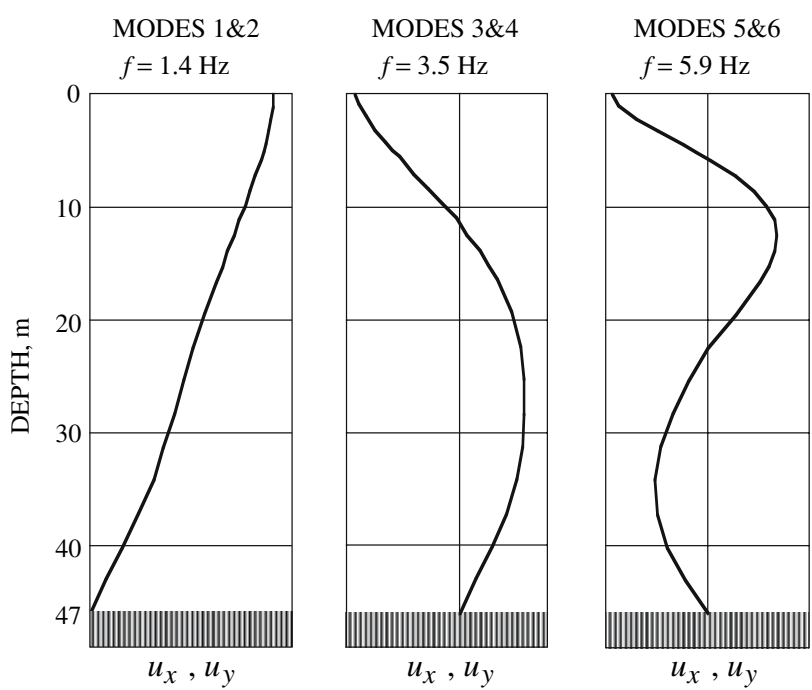

Fig. 24 First six modes of vibration for the 47-m thick sediment deposit at LSST-downhole array DHB site in Lotung, Taiwan. Figure reproduced from Ref. [6]

generated from combined stochastic-deterministic simulations. Finally, a suite of strong ground motions was applied to the base of the sediment deposit to better understand the pattern of inelastic deformation. Results of the hypothetical earthquake simulations strongly suggest that the notion of yield acceleration along with the Newmark sliding block method may not adequately capture the essential features of residual coseismic deformation of horizontally layered sediment deposits. Both the residual and maximum relative displacements correlate poorly with the peak ground acceleration, with some very strong ground motions producing relatively small residual sediment deformations.
This indicates that residual deformation does not depend on the acceleration per se, but rather, on the entire character of the ground motion. Therefore, to better estimate the residual coseismic sediment deformation it is proposed that a time-domain analysis using a well-calibrated nonlinear local site response model, such as the one utilized in this paper, be carried out whenever possible.

Acknowledgments We thank Dr. H.T. Tang and Electric Power Research Institute for providing the digitized ground motion data for the Lotung earthquakes. We also thank Dr. H. Haddadi for providing raw ground motion data for Gilroy 1, and Dr. C. Menun for allowing us to use the program CARDINAL. This research was funded by NSF Grant No. CMS-0201317.

\section{References}

1. Ambraseys NN, Menu JM (1998) Earthquake induced ground displacements. Earthq Eng Struct Dyn 16:985-1006

2. Anderson DG, Tang YK (1989) Summary of soil characterization program for the Lotung large-scale seismic experiment. In: Proceedings of EPRI/NRC/TPC workshop on seismic soil-structure interaction analysis techniques using data from Lotung, vol 1, Taiwan, EPRI NP-6154, Electric Power Research Institute, Palo Alto, CA, pp 4.1-4.20

3. Andrade JE, Borja RI (2006) Quantifying sensitivity of local site response models to statistical variations in soil properties. Acta Geotech 1:3-14

4. Borja RI, Amies AP (1994) Multiaxial cyclic plasticity model for clays. J Geotech Eng 120:1051-1070

5. Borja RI, Chao HY, Montáns FJ, Lin CH (1999) Nonlinear ground response at Lotung LSST site. J Geotech Eng 125:187197

6. Borja RI, Chao HY, Montáns FJ, Lin CH (1999) SSI effects on ground motion at Lotung LSST site. J Geotech Eng 125:760-770

7. Borja RI, Lin CH, Sama KM, Masada GM (2000) Modeling nonlinear ground response of non-liquefiable soils. Earthq Eng Struct Dyn 29:63-83

8. Borja RI, Duvernay BG, Lin CH (2002) Ground response in Lotung: total stress analyses and parametric studies. J Geotechn Geoenviron Eng 128:54-63

9. Boore DM, Bommer JJ (2005) Processing of strong-motion accelerograms: needs, options and consequences. Soil Dyn Earthq Eng 25:93-115

10. Boore DM, Stephens CD, Joyner WB (2002) Comments on baseline correction of digital strong-motion data: examples from the 1999 Hector Mine, California, earthquake. Bull Seismol Soc Am 92:1543-1560

11. Bradner H, Reichle M (1973) Some methods for determining acceleration and tilt by use of pendulums and accelerometers. Bull Seismol Soc Am 63:1-7

12. Elgamal AW, Zeghal M, Tang HT, Stepp JC (1995) Lotung downhole array. I: Evaluation of site dynamic properties. J Geotech Eng 121:350-362

13. Electric Power Research Institute (1993) Guidelines for determining design basis ground motions, vol 1. Method and guidelines for estimating earthquake ground motion in North America. Technical report no. TR-102293, Electric Power Research Institute, Palo Alto, CA

14. Hardin BO, Drnevich VP (1972). Shear modulus and damping in soils: design equations and curves. J Soil Mech Found Div ASCE 98:667-692 
15. Hashash YMA, Park D (2002) Viscous damping formulation and high frequency motion in non-linear site response analysis. Soil Dyn Earthq Eng 22:611-624

16. Hilber HM, Hughes TJR, Taylor RL (1977) Improved numerical dissipation for time-integration algorithms in structural dynamics. Earthq Eng Struct Dyn 5:283-292

17. Idriss IM, Sun JI (1992) Users manual for SHAKE91. Center for Geotechnical Modeling, University of California, Davis

18. Kramer SL (1996) Geotechnical earthquake engineering. Prentice-Hall, NJ

19. Lee MKW, Finn WDL (1991) DESRA-2C: dynamic effective stress response analysis of soil deposits with energy transmitting boundary including assessment of liquefaction potential. The University of British Columbia, Faculty of Applied Science, Vancouver, BC

20. Li XS, Wang ZL, Shen CK (1992) SUMDES: a nonlinear procedure for response analysis of horizontally-layered sites subjected to multi-directional earthquake loading. Department of Civil Engineering, University of California, Davis

21. Newmark $N$ (1965) Effects of earthquakes on dams and embankments. Géotechnique 15:139-159
22. Pyke RM (1992) TESS: a computer program for nonlinear ground response analyses. TAGA Engineering Systems and Software, Lafayette

23. Rodriguez-Marek A, Bray JD (2006) Seismic site response for near-fault forward directivity ground motions. J Geotech Geoenviron Eng 132:1611-1620

24. Schnabel PB, Lysmer J, Seed HB (1972) SHAKE—a computer program for earthquake response analyses of horizontally layered sites. Report no. EERC 72-12, University of California, Berkeley

25. Shakal AF, Petersen PD (2001) Acceleration offsets in some FBA's during earthquake shaking (abstract). Seism Res Lett $72: 233$

26. Tang HT (1987) Large-scale soil-structure interaction. EPRI NP5513-SR Special Report, Electric Power Research Institute, Palo Alto, CA

27. Trifunac MD, Todorovska MI (2001) A note on the useable dynamic range of accelerographs recording translation. Soil Dyn Earthq Eng 21:275-286

28. Zeghal M, Elgamal AW, Tang HT, Stepp JC (1995) Lotung downhole array. II: Evaluation of soil nonlinear properties. J Geotech Eng 121:363-378 